\title{
Objective and Subjective Judgements in Environmental Impact Analysis
}

\author{
$b y$ \\ William H. Matthews, Ph.D. (M.I.T.) \\ Arthur D. Little Associate Professor of Environmental Sciences and Engineering, Department of Civil Engineering, Massachusetts \\ Institute of Technology, Cambridge, Massachusetts 02139, U.S.A.; Visiting Faculty Member, Centre d'Etudes Industrielles, \\ 1231 Conches, Geneva, Switzerland.
}

\section{INTR ODUCTION}

During the past ten years, environmental issues have steadily emerged as important considerations in the planning and implementation of major projects by the public or governmental and private sectors of the population of industrial countries. This development has presented, to those concerned with environmental conservation, an unprecedented set of opportunities to influence important decisions. It has also confronted them with enormous challenges to determine how these environmental considerations can be incorporated into decision-making processes in a manner that will be consistent with the expectations, capabilities, and responsibilities, of a wide variety of decision-makers and the people whom they represent.

These opportunities and challenges have been strongly felt in the United States as a result of the National Environmental Policy Act of 1970 (U.S. Council on Environmental Quality, 1970) which required all Federal agencies to prepare a statement of the environmental impacts of their major proposed activities. Public and private organizations in other countries are subject to varying degrees of legislative or public pressure to examine the probable effects on the environment of their activities, before proceeding to implement any major plans.

As a result of these developments, much work has been done to determine how the analysis of what are commonly called 'environmental impacts' can be undertaken systematically. The following references are indicative of the diverse nature of these efforts: Quade (1970), Leopold et al. (1971), Whitman et al. (1971), Bagley (1972), Baumgold \& Enk (1972), Bishop (1972), Ditton \& Goodale (1972), Kneese \& Bower (1972), Stover (1972), Daetz \& Schlesinger (1973), Sorenson \& Moss (1973), and U.S. Council on Environmental Quality (1973).

One of the most persistent and bothersome difficulties in efforts to develop techniques or methodologies for environmental impact analysis has been the need to differentiate, and make explicit, the objective and the subjective jugdements that are required. In some of the earlier attempts it was implicitly assumed that such an analysis could be undertaken by employing purely objective data, scientific judgements, and evident conclusions, and that it would not be necessary for the analyst to introduce any value-judgements-a role reserved for the 'decision-maker'. In some of the more recent efforts, the subjective nature of the analysis is explicitly recognized, but it is often assumed that the analyst can somehow make these subjective judgements in an 'objective' manner-thus eliminating the need to face the issues involved in introducing various types of values into the analysis.

The present paper is based on the premise that the analysis of environmental impacts requires both objective and subjective judgements at almost every stage, and that if these two types of judgements are confused in the mind of the analyst, or in his final product, then the effectiveness-and even the credibility - of his work will be seriously compromised. In order to aid the analyst in these distinctions, the present paper will discuss the types of objective and subjective judgements that must be made at each of the steps taken in arriving at the final analysis.

For the purposes of this paper, objective judgements are those which involve or use facts that are observable or verifiable-especially by scientific methods-and which do not depend on personal reflections, feelings, or prejudices. This does not suggest that knowledgeable persons will always make the same objective judgements. There is much disagreement among scientists and other scholars on important points of theory and interpretation of verifiable data. Thus objective judgements may indeed be different and still be objective. In these cases, however, there is a danger of subjective considerations slipping in-as will be discussed later.

On the other hand, subjective judgements are those which are made on the basis of values, feelings, and beliefs. They generally vary widely from person to 
person, group to group, institution to institution, and society to society. Subjective judgements can be changed, but this requires a change in the underlying values of the party that is making the judgement; objective judgements, conversely, can be changed by the simple introduction of new objective data or acceptable interpretations. With respect to environmental impacts, the objective judgement describes the impact (for example, the number of fish that would be killed under certain circumstances) whereas subjective judgements are made with respect to how people feel about that 'fact' (for example, one citizen may not care at all while another, who enjoys fishing, may be extremely upset).

\section{ANALYZING ENVIRONMENTAL IMPACTS}

Before discussing the steps to be taken in environmental impact analysis, it is useful to consider the fundamental cause of environmental problems. It is essential to realize that the disruption of the environment is not a goal or an end of any specific activity. It is rather the by-product of activities or the means through which they are conducted. These activities have in general been initiated to fulfill very important food, shelter, security, and other physical or emotional needs. In the process of filling these needs (and wants), Man in his inventiveness has determined how to use and manipulate his environment. Sometimes he has used environmental resources directly (such as wood or oil) and sometimes he has used them indirectly (such as for a free disposal system).

Recently, societies have begun recognizing that part of the costs which they are paying for those goods and services that they 'need' involve the loss of some environmental resources. This has created a conflict. It is a conflict between the desirability of continuing to obtain what they 'need' or the way they obtain it versus the desirability of not despoiling, degrading, or destroying, finite environmental resources. It is not a choice of giving up something 'bad', such as polluting or a technology; it is a choice of giving up or of paying more for a commodity or service that they had previously decided they wanted and that someone has undertaken to provide for them.

Thus in the overall context there are no pure 'villains'. There are, however, people and organizations who meet other persons' needs while at the same time depriving them (or others) of other things that they also value. Resolution of these conflicts will involve change, and can thus deeply affect the legitimate interests of some segments of the society who now find some of the consequences of their socially desirable activities on a new list of undesirable costs.

This is the great dilemma of resolving conflicts in environmental management. If a society decides that pollution of a certain river is undesirable, it cannot simply close the polluting plant, for the plant's business is not to pollute but to create products that people want to buy and jobs for people who need to work. If a society decides that it is using too many trees, it cannot simply force lumber companies to stop cutting trees, as their business is not to kill trees but to provide wood and paper products for an enormous number of activities throughout the entire society.

Analyses of environmental impacts are undertaken to supply, in a systematic way, the information that societies need to resolve these conflicts. As the conflicts are the result of clashing values, the analyses must somehow address and incorporate these values; otherwise they will prove to be largely irrelevant-even though they may be replete with facts, figures, and imaginative theories of cause-effect relationships. However, when they do include the value judgements, these must be incorporated in a very explicit and careful manner or the analysis itself will become an issue of conflict rather than a means of resolving a larger conflict.

Finding the balance between these extremes presents a great challenge to the environmental analyst, coordinator, and manager. An environmental impact analysis-which must include some statement, definition, and delineation, of specific environmental 'problems'-represents by its very nature the products of numerous scientific, social, and political, decisions. Without understanding the types and mixes of decisions and the order in which they are taken, the analyst, and the decision-maker who uses his work, may feel that they are proceeding on the basis of firm, objective scientific analysis when in reality the implicit value-judgements have been paramount in setting the constraints within which the problem can be analyzed.

In an effort to help scientists and analysts to avoid this outcome, this paper will discuss some of the objective and subjective judgements that must be made in the following major steps of predicting, analyzing, and judging, environmental impacts :

\section{Identifying Major Activities}

Selecting Environmental Components

Selecting Types of Impacts

Assessing the Possibilities and/or Probabilities of Occurrences

Determining the Degree of the Impacts

Determining the Time-frame of Impacts

Designating Impacts as Positive, Neutral, or Negative

Determining Trade-offs among Activities and Impacts.

Although these steps can only be discussed one-at-atime and in a linear manner, this does not suggest that they can be undertaken in such a straightforward 
way as this. Environmental impact analysis is a highly iterative process. Each new group of data or piece of information quite often suggests the inclusion of related information or values in various steps of the process; consequently, parts of the analysis must be redone, and only rarely can definitive conclusions be reached in one step without some inputs from other steps.

\section{Identifying Major Activities}

The discussion in the rest of this paper will expand upon the following relationships:

Activities and/or their By-products $\rightarrow$ Impact on Environmental Components.

Many activities (such as strip-mining) impact upon some environmental components directly (such as coal depletion and land destruction) and upon other components indirectly through their by-products (such as aquatic biota through water pollution from erosion, or human health through air pollution from the mining operations). In general, the analyst must catalogue the major activities and by-products which would result from a project that is proposed or that is already resulting in environmental problems. This requires an extensive analysis of the various phases of the project-construction, operation, expansion, maintenance, and ultimate disposition. It also requires examination of the inputs and outputs of the processes involved. To determine the environmental impact of products, the production, use, and disposal, phases and processes must each be studied. The potential of accidents should also be considered.

These lists of activities and their by-products are objective in nature. They are straightforward listings of functions, products, effluents, and so on, that any group of skilled technical persons would compile in roughly the same manner as any other equally skilled group. There is no problem with objectivity as long as one is thorough and comprehensive. However, in a project of any serious complexity, one cannot be comprehensive-or the listing of activities and their by-products would be so prohibitively long that there would be too little time or too few resources to analyze the impacts resulting from them.

Judgements must be applied to narrow the list-and while they may appear to be objective, they are usually based on a set of subjective judgements. For example, a construction engineer may assert that the bulldozing operation at a new plant-site has no adverse effect on the environment-apart from the land already set aside-and may thus leave that activity off the list of possibly harmful items. This may be the result of a careful and objective determination of the lack of effects of the bulldozing on parts of the environment that are of 'importance' - such as through noise pollution-even though the effects on 'unimportant' components of the environment, such as the ant colonies that would be destroyed, might be significant.

This example demonstrates both the subjective nature of this step of analysis and also the iterative and interconnected nature of the entire analysis process. Without some criteria for 'important' and 'unimportant' impacts on environmental components, there is no way that the list of activities and by-products can be reduced by a single item. These criteria are subjective in nature, and they are derived from other steps in the analysis process which will be discussed below. If the other steps are not made first, the listing of activities becomes an endless and senseless chore. But if the activities are not listed first, then how can impacts be identified and analyzed?

This difficulty is usually resolved in two ways: first, by a combination of working on many of the steps simultaneously and of selectively working through a series of steps for a single activity, impact, or environmental component; and secondly, by utilizing the subjective judgements that have explicitly or implicitly been made on similar activities (for example, during a recent plant construction local citizens may have picketed because the bulldozers disturbed their children's sleeping whereas no one even mentioned all the ant colonies that were destroyed). Using the first of these approaches introduces all of the subjectivity of other steps into this ostensibly objective listing of activities. The second approach may result in the subtle and implicit introduction of subjectivity without the benefit of making it explicit in the other steps. It is especially important to be aware of this latter possibility.

When the 'major' activities and their by-products have been identified, the earlier relationship can be represented as follows: $\underset{m}{\Sigma}$ (Activities) $)_{i}+\underset{\mathbf{o}}{\Sigma}$ (Byproducts $)_{\mathrm{j}} \rightarrow$ Impacts on Environmental Components, where $\Sigma$ B denotes the summation of ' $a$ ' items of ' $B$ ', the ' $c$ ' being a general notation for any item ' $B$ '; $\rightarrow$ denotes 'results in': this general definition will apply to equations throughout the paper.

\section{Selecting Environmental Components}

The selection of those components of the environment that will be considered in the impact analysis is critical. These choices will determine the boundaries of concern about an activity and thus to a large degree determine the very nature of the problems and any potential solutions. There is essentially an infinite list of objectively determinable environmental components and ways of defining relationships among them. Once again, the thoroughly objective analyst will have a never-ending task of listing the components that could be considered in the analysis. Subjective judgements must be introduced in such a manner that 
only 'important' components and relationships are singled out for detailed analysis. The decision must also be made on how 'environment' is to be defined: for example, whether it will include social as well as natural components and relationships.

The concept of 'importance' implies a set of valuejudgements that must be made relative to something, and that are made by a person or group holding those values. Whose values are to be used in setting these criteria for selection - the local conservation group, the multinational corporation, the tourist industry, the government, or some other interested or disinterested parties? The list of 'important' components will vary from group to group, and the reasons for listing the same components may also vary (thus a species of fish may be listed by commercial fishermen and by conservationists for widely opposing reasons).

The analyst must somehow decide whose values he will accept for purposes of deciding which environmental components to consider, and whose he will reject. He should explicitly specify whatever criteria he chooses in making these critical choices-whether they are based on social, political, or ecological, grounds or on his own personal or institutional biases. When once this has been done, his analysis is no longer an 'objective analysis' but an analysis in which objective determinations are made within the context of subjectivelychosen parameters. Thus even one of the most 'scientific' of all the steps-selecting environmental components - is ultimately based more on values than on science, if one is to have a manageable list for analysis. When once these selections have been made, the earlier relationship becomes the following:

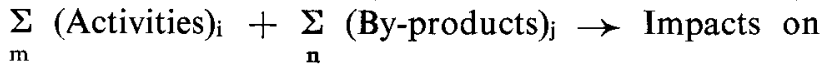

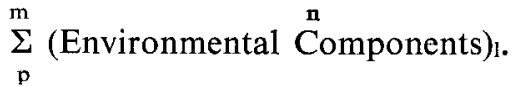

\section{Selecting Types of Impacts}

For any given component of the environment that is affected by some activity or by-product, there are a wide variety of types of impacts that could be considered. For example, if a certain species of plant or animal is affected, then is the impact listed only if the species is eradicated, or if its numbers are reduced below a certain level (what level?), or if its general health or well-being is affected (how much?), or if the impact on the species creates another set of impacts on other species or on biological, geological, chemical, or social, processes-and so on?

The identification of the types of impacts-such as extinction, mortality, morbidity, and instability-for any component, is an objective process. But here again the analyst is overwhelmed with the theoretical length of such a list, as was the case in the previous steps. In addition there is a new and profound difficulty-the state of scientific understanding is very poor with respect to the types of impacts that are possible, and to their ramifications on related parts of the environment. This situation has not improved at all markedly since a group of prestigious scientists on the National Science Board (1971) reported the following to the President of the United States as their 'principal conclusion':

'Environmental science, today, is unable to match the needs of society for definitive information, predictive capability, and the analysis of environmental systems as systems. Because existing data and current theoretical models are inadequate, environmental science remains unable in virtually all areas of application to offer more than qualitative interpretations or suggestions of environmental change that may occur in response to specific actions.'

The necessity of reducing the list of impacts to those of 'importance', coupled with the limitations of the scientific community to provide guidance on the implications of many impacts, forces the analyst to make innumerable subjective judgements. When objective facts are lacking, he must rely on the only things available — values, feelings, beliefs, and prejudices. It is useless to debate whether he should do this, for he has no choice if he is to proceed with what information he does have and make decisions on how to allocate resources to supplement his information in carefully selected areas. There is, however, an important question of whose values and biases he adopts for purposes of this selection process, and how explicit he is about these choices in his report. The issue is not whether he makes subjective judgements but the degree to which he recognizes when he is doing it, his basis for doing it, and his responsibility to make these explicit in his analysis.

The principal subjective judgements that must be made are with respect to the following: What types of damage or enhancement of each specific environmental component will be noted (for example, the spectrum from extinction to inconvenience, or from irreversible process to self-correcting perturbation); how much damage or enhancement to each specific component will be considered 'important' enough to require a full analysis (for example, the extinction of tunas versus Peregrine Falcons, or the general reduction in health of a city versus that of a seal colony, or a few per cent yearly change in local precipitation versus a few degrees steady-state change in global temperature); and finally, and very profoundly, what types of second-, third-, and fourth-order effects of the primary impact will be considered and how much creative energy will be devoted to identifying these. The following example illustrates this last point: one activity of a new plant in a community might be to create new jobs which could have a 'primary' impact of changing the material standard of living in the community; this might then result in a change in the dominant life-styles, which in 
turn could result in an influx of different types of people, thus creating changes in ethnic and religious groupings which could then begin changes in the cultural fabric of the community-and so on.

The compilation and analysis of the objective data that exist on impacts, and the application of the types of subjective judgements discussed above, combine with the previous steps to produce the following relationship:

$\sum_{\mathbf{n}}(\text { Activities })_{\mathrm{i}}+\underset{\mathbf{m}}{\mathbf{S}}(\text { By-products })_{\mathrm{j}} \rightarrow \underset{\mathbf{0}}{\Sigma}(\text { Impacts })_{\mathrm{k}}$ $\Sigma$ (Environmental Components)

$\mathrm{p}$

This relationship is useful in illustrating how complex the analysis is, especially if the summation totals- $n, m, o$, and $p$-are very large. The only way that they can be kept small is by making numerous subjective judgements, using such criteria as 'major' or 'important'. If an analysis that is not absolutely comprehensive in its coverage of a complex environmental 'problem' claims to be objective, then it is probably either being misrepresented wilfully or unknowingly or else the analyst is so in tune with the values, mores, and preferences, of the recipients of the analysis, that both writer and reader share and accept the same implicit subjective constraints on what is to be analyzed objectively. Such a state of harmony is rare among concerned parties who scrutinize analyses of most environmental issues.

: The relationship given above is not meant to be mathematically representative of how one would list the categories for analysis. Instead of a long list of factors summed together, there would be a series of relationships. A certain activity might impact in five specific ways on a certain environmental component, in three ways on another, and so on. Alternatively, the analysis could proceed by noting that a certain environmental component is impacted upon in four ways by a specific activity, in five ways by a specific by-product, in two ways by the third-order effect of another activity, and so on. The relationship thus describes a multitude of cases which must each be analyzed further in the steps to be discussed. The simplest case is represented in the following way:

$$
\begin{aligned}
& (\text { Activity })_{\mathrm{A}} \rightarrow(\text { Impact })_{\mathrm{B}} \text { on (Environmental } \\
& \text { Component })_{\mathrm{C}} \\
& (\text { Activity })_{\mathrm{A}} \rightarrow(\text { Effect })_{\mathrm{BC}}
\end{aligned}
$$

where for purposes of this paper (Effect) BC is the result of (Impact) $)_{B}$ on (Environmental Component) $)_{C}$.

\section{Assessing the Possibilities and/or Probabilities of Occurrences}

To a large degree, the previous steps have produced hypothetical listings of potential cause-effect relationships between activities and environmental components. It is now necessary to determine the possibil- ity and/or probability that any given effect-a specific impact on a specific environmental component-will indeed occur as a result of the proposed project or activity, or from an accident. The effect may either be certain or it may be uncertain within some probability range. If it is uncertain it should be referred to as a 'risk' rather than an 'effect'.

In 'risk' analysis and probability assessment, the state of scientific knowledge is such that it is generally impossible to obtain a specific probability such as 0.2 or 0.8 . Often it is only possible to speak about 'likely' and 'unlikely'. The analyst must be very clear as to what he means by this: for example, greater than 0.75 or less than 0.25 . The modifications of such ambiguous phrases are endless: for example, 'highly likely', 'very unlikely', almost certain', 'negligibly small', and so on. The interpretation of such phrases will vary from person to person and context to context (how small a risk is 'neglibly small' if its occurrence were to obliterate 100,000 persons?). Clearly such terms contain subjective judgements.

In principle, the determination of whether an activity will have an 'effect' (with certainty) or present a 'risk' (with some probability) could be purely objective if the level of scientific knowledge were adequate to support these conclusions. As noted earlier, this is not often the case; yet many judgements have to be made. These are often regarded as 'professional' judgements, and there can be much disagreement among scientists and professionals without any introduction of the type of subjective judgements that this paper has been discussing. However, when the objective grounds for judgements are very limited and speculation begins to replace supportable theoretical conjecture, it is possible for subjectivity to creep in-often without the analyst realizing it. In general, the definitive conclusion of 'certainty' would be wholly objective only with the full consensus of all knowledgeable parties. 'Risk' assessments, on the other hand, are very susceptible to the introduction of subjectivity.

Whether one is liberal or conservative in assessing possibilities and probabilities is often a function of personal, professional, and institutional, biases and these are often used by scientists and analysts to supplement scientific intuition-particularly with respect to 'safety factors'. Something may, on the basis of the best available data, seem slightly 'unlikely'; but if the person making the judgement feels, perhaps at an unconscious level, that the component or the effect is so 'important' that it is better to be safe than sorry, he may conclude in good professional conscience that it is really slightly 'likely' for purposes of the analysis. In areas where there are very few experimental data and the theories are often little more than sophisticated speculation, the emphasis put on the 'doomsday' theories or the 'things-will-work-themselves-out' theo- 
ries can vary according to individual and professional tastes.

Unfortunately, such lack of empirical or firm theoretical grounding often occurs in the environmental sciences-particularly in those dealing with key interrelationships such as epidemiology, ecology, atmospheric sciences, and oceanography. Thus the analyst must not only be on guard for sloppy scientific judgements, but, even in this apparently objective area of probability assessment, he must also be aware of potential value-biases in the conclusions.

When the determinations discussed in this section are made, the previous relationship can be elaborated as follows:

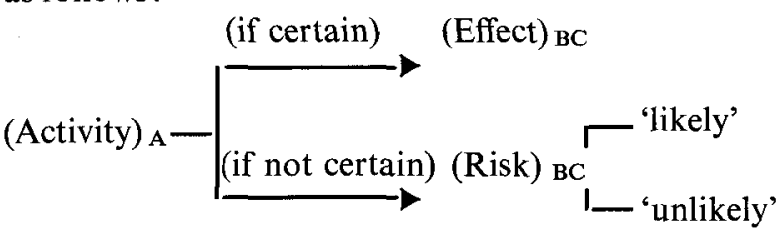

\section{Determining the Degree of Impacts}

The analysis of the change that occurs in an environmental component as a result of a present or predicted impact, is a really objective process as long as the scientific base on which conclusions are made is strong. The same difficulties that were discussed in the previous section may arise, however, and may have the same consequences with respect to subjective judgements that are being implicitly introduced.

Such subjective judgements are very different from those which were discussed in the section on selecting types of impacts-what types, how much, and what level, of impacts are to be considered. However, any objective judgements that may be made about the degree of an impact are arrived at within the value context set by the selection of type. This is a very important point for the scientist and analyst to recognize: when once the stage is reached of determining, qualitatively and quantitatively, the amounts of changes that occur for a specific effect, the 'problem' has already been almost totally defined by parameters of a subjective nature. If the analyst limits himself solely to the assessment of degree, then he can usually manage to maintain credibility as an 'expert'. However, if he presents results of his analysis that include other steps discussed here, his 'expertness' will be compromised by his or others' values.

It was noted earlier that these steps can be taken in many orders and sequences; but this step of determining the degree of an impact is often the first one taken towards pointing out the need for conducting or expanding an analysis, and through it scientists have made many important contributions to environmental management and conservation. For example, the scientific predictions on the degree of impact of SSTs on stratospheric composition and the resulting impacts on health and climatic processes, played a large part in the debates that ended in the decision not to build SSTs in the United States. Scientific assessments of degrees of impact which might result from changes in environmental processes without relating the causes of the changes to any particular activities, can stimulate society to be aware of undesirable possibilities and make it more attentive to activities that might have such effects; for example, a prediction that a reduction of the ozone layer in the stratosphere could result in increased incidences of skin cancer has already brought such diverse activities as SST transport and aerosol deodorant use under close scrutiny.

\section{Determining the Time-frame of Impacts}

Another important dimension in assessing environmental impacts is the time-scale in which an effect will or might occur. Sometimes this determination is relatively straightforward and is thus based primarily on objective judgements; an example is the time it would take, under certain conditions, for the antarctic ice-cap to melt (it should be noted that the estimate may be incorrect but is now widely agreed upon in the scientific community). In other cases the determination of the time-frame may be nebulous at best-'for example, the length of time it would take for eradication of the Black-footed Ferret to affect the stability and/or diversity of an ecosystem, and the time it would take the ecosystem to reach a new state of equilibrium. In such cases, the types of subjective judgements discussed in the section on probabilities may begin to occur in the scientific analyses.

The time-frame is very important in political decision-making (the motivation for the analysis), especially if an undesirable impact is likely to occur within a few years-the normal time-horizon of the politician or high-level administrator. In most societies at present the major emphasis appears to be on reducing short-term adverse effects and either ignoring long-term effects or hoping that a way will be found in time to avoid them. A word often used to describe the short-term possibilities is 'imminent'. The operational definitions of imminent, and of its opposite, are highly subjective in nature. Whether these labels are used to denote two days, two weeks, two years, two decades, or two generations, is a subjective decision and will reflect the values of the labeller.

There are also uncertainties in determining if an adverse effect or risk will be imminent if a given activity occurs. These judgements are primarily objective, but once again subjective conservatism or liberalism can enter-usually implicitly. Although it becomes rather cumbersome to do so, it is often necessary to qualify the judgement of imminence with a 'likely' or 'unlikely' that reflects the lack of a strong scientific basis. Thus one may have to talk about a 
'likely imminent unlikely risk', or use some similarly jumbled phrase.

Decision about the time-frame can also be influenced by such factors as irreversibility and non-renewability. These can be determined objectively, but how they will be viewed will depend on subjective judgements.

\section{Designating Impacts as Positive, Neutral, or Negative}

While the determination of degree of impact is almost purely objective, the designation of those impacts as positive (beneficial), neutral, or negative (adverse), is purely subjective. The following experience, related by the former head of the U.S. Environmental Protection Agency (Ruckelshaus, 1974), makes this general point very graphically:

'In June of 1972 I was administrator of the U.S. Environmental Protection Agency and in that capacity was a delegate to the first world-wide conference on the environment in Stockholm, Sweden. While there I hosted a luncheon for all the African delegations south of the Sahara. For four hours all of us present discussed the environment as a global issue. Before that luncheon I knew intellectually that the less-developed countries of the world viewed the environment differently than we did. Afterward I understood the difference viscerally... I was trying to convince them that they needn't repeat our mistakes in the process of meeting the legitimate material aspirations of their people. I shall never forget how during my plea the minister of the environment from Ghana jumped to his feet and shook his finger at me, saying "You just don't understand. Let me give you an example of how my people view the environment. If you discovered a widely-used pesticide was killing fish, your people would demand that you ban it. In Ghana my people would use it - to kill fish-and then eat them. That a pesticide had such lethal capacity would be good news to them." Obviously, the problems of protecting the environment in Ghana were not the same as in America.'

\section{Determining Trade-offs among Activities and Impacts}

The 'final' step in an environmental impact analysis is to relate the impacts, and all the associated judgements about them, to the activities that cause interested people to explore the implications of accepting the impacts or of modifying or ceasing the causal activities. This is often referred to as performing a 'cost/benefit [C/B] analysis'. Such an analysis is really made up of numerous individual $\mathbf{C} / \mathrm{B}$ analyses of a variety of factors such as the narrow economic $\mathrm{C} / \mathrm{B}$ of an activity, the specific ecological $\mathrm{C} / \mathrm{B}$ of a specific impact on a specific component of the environment, and the political $\mathrm{C} / \mathrm{B}$ of controlling an activity in a certain manner.

The objective of the $\mathrm{C} / \mathrm{B}$ analysis is to provide information that will ultimately be used in making two classes of basic environmental management decisions: those on 'acceptability' or 'unacceptability' of adverse effects, and those on modifications, alternatives, or controls, that would ensure that the 'costs' do not exceed the 'benefits' of any given activity. The relationship among the steps discussed in this part of the paper with these two social and political decisionmaking processes is shown schematically in Fig. 1. It

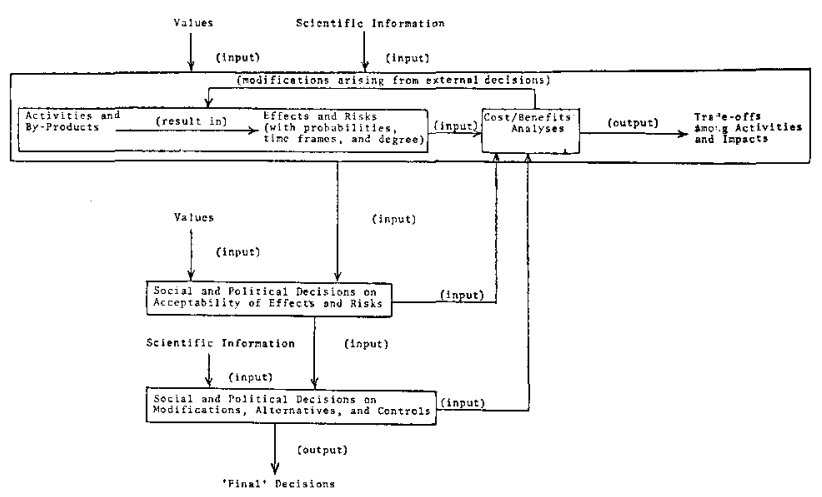

FIG. 1. Relationships among steps in environmental impact analysis and social and political decision-making processes.

can readily be seen that this is a very complex, dynamic process in which all the judgements are dependent on one another. The decision on 'acceptability' of adverse effects cannot be made without criteria, and these criteria are dependent on how the overall $\mathbf{C} / \mathrm{B}$ of a given activity is perceived; for example, the loss of a 'beneficial' predator, due to a pesticide use that eliminates a pest, may be acceptable if the vegetation to be saved is of cotton but not if it is of petunias. On the other hand, one cannot determine that the $\mathrm{C} / \mathrm{B}$ ratio for cotton crops will always be less than one, regardless of what types of adverse effects might have to be tolerated. Thus, the 'environmental costs' that a society is willing to accept are dependent on their relation to the total $\mathrm{C} / \mathrm{B}$ of the activity, which is itself made up in part by the 'environmental costs'.

This presents the classic problem encountered in interconnected systems, of needing to have a piece of information from $\mathrm{B}$ to determine $\mathrm{A}$-but realizing that the required information can only be derived from $\mathrm{A}$ ! The only approach that works is an iterative one; but this requires some assumptions, in the C/B analyses, about how 'society' will judge the acceptability of adverse effects and the desirability of modifications, alternatives, or controls. This places the analyst squarely within the province of the proverbial 'decision-maker', and he must be very careful not to arrogate the authority that the decision-maker has to articulate and set priorities among conflicting values.

The best safeguard is for the analyst to provide a scrupulously explicit account of the value-assumptions made, and to express these value-assumptions in terms such as 'If this effect is judged unacceptable because of the following reasons..., then the costs appear to outweigh the benefits if the only benefits considered are the following.... On the other hand, if the following additional benefits are considered..., 
and the reasons for unacceptability do not include the following reasons..., then the benefits would outweigh the costs.' Clearly such elaborations cannot be developed endlessly. Thus, in the absence of instant feedback from society or its decision-makers on every new point in the analysis as it arises, the analyst must introduce the most fundamental subjective judgements of all - the very acceptability of adverse impacts and of efforts taken to reduce them.

To complicate the picture further, it is not possible to assess ultimately an overall $\mathrm{C} / \mathrm{B}$ relationship and determine acceptability of an activity (and its effects) without considering the effects and $\mathrm{C} / \mathrm{B}$ of any controls, modifications, or alternatives (in the rest of this section these three will be referred to as controls), that might be instituted to mitigate potential 'environmental costs'. These controls will introduce other C/Bs, directly or indirectly, by modifying all of the previous analyses - any control option will set up a new situation requiring one to examine new components, new impacts, new probabilities, and so on, as well as to determine the new costs and benefits at every stage (including the newly-added control). The final layer of complexity is a very familiar and frustrating problem: virtually all of the individual $C / B$ analyses contain judgements that are not quantifiable, and are not even comparable with one another, so that comparison of a C/B analysis on one aspect (such as health) with another aspect (such as economics) is almost always intractable. This is popularly called 'mixing apples and oranges to make decisions about grapefruit'.

Having acknowledged that one cannot add together, at least in any sort of an algebraic manner, the various costs and benefits, the types of equations that would be used if one could do this will nevertheless be suggested below for purposes of illustration. First, without any controls (where $\mathrm{C}$ designates costs and $\mathrm{B}$ designates benefits):

$$
\begin{aligned}
& \mathrm{C}_{\text {Total }}=\mathrm{C}_{\text {Activity }}+\Sigma \text { (impacts) } \Sigma \text { (components) } \\
& \mathrm{C}_{\text {Effects }_{\mathbf{k} \mathbf{1}}} \\
& \mathbf{B}_{\mathbf{r}}=\mathbf{B}_{\mathrm{A}}+\underset{\mathbf{o}}{\Sigma} \underset{\mathrm{p}}{\sum} \mathbf{B}_{\mathrm{E}_{\mathbf{k}}}
\end{aligned}
$$

If it is found that the $C_{T}>B_{T}$, or that the net benefits are not great enough, controls (co) may be sought to mitigate the effects. This will change all the determinations and calculations; for example, $C_{A}$ will become $\mathrm{C}_{\mathrm{A}_{c o}}$, or the cost of the activity as modified by the control. $\mathrm{C}_{\mathrm{co}}$ is the direct cost of the control. This yields:

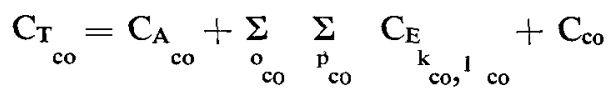

and similarly for $\mathrm{B}_{\mathrm{T}_{\mathrm{co}}}$. This could also be done for many controls $\left(\mathrm{Co}_{1}, \mathrm{co}_{2}, \ldots\right)$. One cannot simply compare $\mathrm{C}_{\mathrm{T}_{\mathrm{co}}} / \mathrm{B}_{\mathrm{T}_{\mathrm{co}}}$ with $\mathrm{C}_{\mathrm{T}} / \mathrm{B}_{\mathrm{T}}$ to determine if a control is warranted, for the same reason that onecannot explicitly use such equations-the types of costs in one may be very different from the other, so they are not directly intercomparable. These have been elaborated to demonstrate the interrelatedness suggested in Fig. 1 -not to prescribe a way of dealing with a problem that somehow must be solved (because analyses must be performed and decisions must be made). It also has to be noted that the technical basis for using a cost/ benefit ratio versus a calculation of net benefits for the purposes of impact evaluation is a subject of considerable controversy-see, for example, De Neufville \& Stafford (1971).

The analyst must have some explicit subjective criteria on which to base his investigation of trade-offs among activities, impacts, and any controls that might be possible. These are, in fact, not very different from those he has to use throughout the other steps of the analysis. Reducing the list of environmental components to be considered in the analysis is equivalent to judging that any impact on them is 'acceptable', while leaving components on the list suggests that, under some circumstances, adverse impacts on them would be 'unacceptable.' The same could be said for every step. Thus, the analyst already has some sort of 'value framework' that will aid and will influence the final step of determining the various trade-offs.

\section{ADOPTING A 'VALUE FRAMEWORK'}

This paper has shown that, at every stage of an environmental impact analysis, subjective judgements must be made. These are of necessity based on values, feelings, beliefs, and prejudices, and are functions of the personal, institutional, professional, and societal, contexts of the analyst. The only way that 'decisionmakers', and the people whom they represent, can prevent being overly influenced by the values that must be introduced in the process of an analysis, is to insist that the value-judgements and their implications be made explicit. To do this the analyst must be aware of when he is making subjective judgements, and of the nature of the 'value-framework' which he uses.

It is impossible to develop such a framework with the specificity needed to make detailed judgements, and with the generality to be useful in very many cases. In addition to the problems caused by the fact that values vary with time and context, there is the overriding political question of which group's articulation of values and principles represent those of the society. The analyst is subject to many pressures but has very little unambiguous guidance.

Although this paper cannot present a useful and operational value-framework, the author can suggest 
some of the most general types of environmentallyrelated values and priorities that seem to be operating in his own country (the United States). This exposition is not based on a scientific analysis but is given to suggest how one might begin constructing a valueframework that would provide the analyst with some basis for proceeding with his work.

Environmental impact analysis, through the final step of assessing trade-offs, requires some assumptions about the way in which society views economic, human health, environmental, social, and political, costs and benefits. It is very difficult to operationalize these concepts. The easiest and most straightforward appears to be the 'economic' one, because it is, in principle, quantitative-even though the uncertainties involved in the analyses may overshadow this advantage. 'Human health' is relatively straightforward with respect to soundness of body in terms of morbidity/mortality (though one may not be able to determine the figures), but it is much more difficult to generate quantitative (or even convincing operational) criteria for soundness of mind, and even harder for the soul.

In theory it should be possible to decide on operational criteria for assessing 'environmental costs and benefits' of an action if this refers to the 'natural' environment, because it is generally believed that the laws of Nature are orderly and can be determined. However, even if they are indeed orderly, these laws of Nature have, in general, not been determined, and one must deal with very non-quantifiable issues-such as the effects of changes in diversity, stability, and trophic webs. This problem has already been seen in almost every phase of analyzing impacts. Theorists disagree over whether one can ever expect operational criteria for 'social costs and benefits'. Individuals and communities do not seem to act in orderly enough manners for social scientists to have figured them out, or even to determine if they will ever be able to do so. 'Political costs and benefits' vary greatly with the individual or groups involved, and political scientists are in about the same state as other social scientists when it comes to providing much rigorous insight into what will or will not result in losses or increases in power (the crux of political criteria) in any given situation.

Thus, as one looks to the natural and social sciences for support, there is not much real guidance; despite many studies, some very useful insights, and a few helpful models, there is very little operational guidance on how to establish general operational criteria. From our past experience with environmental management in the United States, we can perceive how the social and political processes appear to be operating with respect to these types of analyses. The following is the author's modest attempt to illustrate how these perceptions can be made explicit as the first step in developing a value- framework. If controversy is raised over such ventures into societal analysis, this is to be expected and can indeed assist the analyst in the long run. The analyst need not be absolutely correct in choosing his criteria (in fact he could never be); but he must be explicit, so that those who disagree with him can disregard the conclusions that are associated with his controversial assumptions.

In the context of environmental concerns, the highest priority in the United States seemed to be, until relatively recently, 'economic'-as measured by growth of the gross national product (GNP), industry, employment, and the standard of living. In the past couple of decades, 'human health' has emerged as a close second in some cases (such as occupational health), and has even surpassed it in others (such as when carcinogenic compounds or activities are involved). In general, however, human health, especially in areas outside of cancer (for example, from asbestos) and massive deaths (for example, from nuclear reactor accidents), is often given a second priority to the economic criteria listed above. With respect to soundness of mind and soul, society seems only dimly aware that these are issues, and indeed important costs, to be considered against economic benefits. As many of the 'social costs and benefits' are in this category, they likewise do not receive a great deal of attention, though they are gaining ground.

It is hardly surprising that, with such complacency about deteriorating individual and social health, there should be even more complacency about the 'environment'. There are many supporters of the environment; but there does not seem to be enough real understanding on the part of the populace to support very stringent controls on purely environmental grounds (rather than on human health or economic grounds). The highest priority in this area seems to be the group of effects on components of the environment that would directly affect human health (for example, by disease or lack of food). A second, and in some cases first, priority would be those effects that would cause some economic loss (for example, loss of crops, timber, income-producing lands, and so on). The third priority would be to protect the environment for 'its own sake' or 'for posterity'. This is usually a very low priority-unless there is an unusual groundswell and the 'political' reasons become paramount and require it (for example, the imminent extinction of a popular but not economically important species).

This general ordering of criteria on environmental costs and benefits seems likely to remain for the foreseeable future. However, there are a few things that might change it-such as obtaining a better understanding of the relationships between the environment and what is considered as human health, so that people can act more wisely in their own best 
interests by preventing or mitigating environmental effects which would indirectly harm them or their 'quality of life'. Through gaining more knowledge and providing public education, efforts can be made to close the gap between the second and third priority, so that the environment will not always be viewed primarily as an economic resource but as having value in itself and as a contributor to the health of the mind, soul, and society. And, finally, through these new insights society may ultimately be able to make tradeoffs between environment and economics that are based on qualitative criteria as much as, or even more than, on monetary values or their facsimiles.

'Political costs and benefits' are the final and often determining assessments that must be made by the decision-maker. In U.S. society, these have enormous weight because the political arena is where all the diverse values must finally be put in some order of priority. It is important, however, to be sure that 'biopolitical' criteria are not used. According to Caldwell (1968), these are the criteria which determine that something which is politically necessary is biologically acceptable. This is not always so, and society's protection against such irregularity is to be as explicit about 'political' aspects as about other ones, so that the latter will not always exert the overriding influence.

All of the criteria outlined here for determining 'costs and benefits' must be used in deciding whether an activity should proceed, whether an adverse effect is acceptable, and whether modifications, alternatives, or controls, are justified. But they are also used in all those subjective judgements that have been referred to so frequently in this paper. For 'rational' environmental management processes it is necessary to be as explicit as possible about how society feels on these criteria, and how it 'ought' to feel on the basis of the best scientific information available. It is also very important that society, and the decision-makers and analysts who serve it, understand the nature of environmental impact analysis and the judgements that must be made in the process. This paper has been devoted to furthering this latter objective.

\section{SUMMARY}

Analyses of environmental impacts, and descriptions of methodologies for conducting them, have not always been explicitly cognizant of the subjective valuejudgements that must be made in the process of collecting, refining, assessing, and presenting, objective scientific information. This paper has outlined the types of objective and subjective judgements that are made in each of the following major steps of the analysis: identifying major activities; selecting environmental components; selecting types of impacts; assessing the possibilities and/or probabilities of occurrences; determining the degree of the impacts; determining the time-frame of impacts; designating impacts as positive, neutral, or negative; and determining trade-offs among activities and impacts.

The subjective judgements that must be made are based on values, feelings, beliefs, and prejudices, and are functions of the personal, institutional, professional, and societal, contexts of the analyst. If great care is not taken in making these judgements, and in making very explicit the value-framework used, the effectiveness and credibility of the analyst may be sharply reduced. There is also the danger that society and its decision-makers will be presented with an analysis having so many built-in biases that the legitimate role of the decision-makers in assessing the analysis and then making important value trade-offs is seriously compromised. This paper has attempted to make the nature of the process of analysis explicit with respect to the introduction and treatment of values, so that these problems can be understood and, it is hoped, properly managed by both scientists and decisionmakers.

\section{References}

Bagley, M. D. (1972). Aesthetic Assessment Methodology for Environmental Impact Analysis. Technical Note, TN-OED004, Stanford Research Institute, Menlo Park, California: 85 pp.

Baumgold, M. S. \& ENK, G. A. (Eds) (1972). Towarda Systematic Approach to Environmental Impact Review. The Insti-. tute of Man and Science, Rensselarville, New York: 59 pp.

BisHor, A. B. (1972). An approach to evaluating environmental, social and economic factors in water resources planning. Water Resources Bulletin, 8, pp. 724-35.

CALdWell, L. K. (1968). Biopolitics: science, ethics, and public policy. Pp. $423-35$ in The Politics of Science (Ed. W. R. Nelson). Oxford University Press, New York: $x+495$ pp.

DAetz, D. \& Schlesinger, B. (1973). A conceptual framework for applying environmental assessment matrix techniques. Journal of Environmental Sciences, 16, pp. 11-6.

De Neufville, R.-See Neufville, R. De.

DitTon, R. B. \& Goodale, T. I. (1972). Environmental Impact Analysis: Philosophy and Methods. Sea Grant Publication WIS-SG-72-111, University of Wisconsin, Green Bay: $171 \mathrm{pp}$.

KNEESE, A. V. \& Bower, B. T. (Eds) (1972). Environmental Quality Analysis-Theory and Method in the Social Sciences. Johns Hopkins Press, Baltimore, Maryland: ix + 408 pp., illustr.

Leopold, L. B., Clarke, F. E., Hanshaw, B. B. \& Balsley, J. R. (1971). A Procedure for Evaluating Environmental Impact. U.S. Geological Survey Circular 645, Washington, D.C.: $13 \mathrm{pp}$.

National ScIENCE BoARd (1971). Environmental ScienceChallenge for the Seventies: Third Annual Report. U.S. Government Printing Office, Washington, D.C.: 75 pp.

Neufville, R. De \& Stafford, J. (1971). Systems Analysis for Engineers and Managers. McGraw-Hill, New York: xiii + 353 pp., illustr.

QuADE, R. S. (1970). On the Limitation of Quantitative Analysis. Rand Corporation Report 4530, Santa Monica, California: $77 \mathrm{pp}$.

Ruckelshaus, W. D. (1974). Yes-the environment can be saved. Saturday Review: World, Fiftieth Anniversary Special Year-end Issue, December 1974, pp. 38-41. 
Sorenson, J. C. \& Moss, M. L. (1973). Procedure and Programs to Assist in the Environmental Impact Statement Process. University of Southern California, USC-SG-AS2-73: 38 pp.

Stover, L. V. (1972). Environmental Impact Assessment : A Procedure. STV, Pottstown, Pennsylvania: 25 pp., illustr.

U.S. Council on Environmental Quality (1970). Environmental Quality: First Annual Report. U.S. Government Printing Office, Washington, D.C., 1, pp. 243-9.
U.S. Council on ENvironmental Quality (1973). Preparation of Environmental Impact Statements: Guidelines. Federal Register, 38 (147), pp. 20549-62.

Whitman, I. L., Dee, N., McGinnis, J. T., Fahringer, D. C. \& BAKER, J. K. (1971). Design of an Environmental Evaluation System. Battelle Columbus Laboratory, Columbus, Ohio: vii +61 pp.

\section{The Real Crisis Behind the 'Food Crisis'}

The world as we know it will probably be ruined before the year 2000, and the reason for this will be its inhabitants' failure to comprehend two facts. These facts are:

1. World food production cannot keep pace with the galloping growth of population.

2. 'Family planning' will not and cannot, in the foreseeable future, check this runaway growth.

The momentum towards tragedy is at this moment so great that there is probably no way of halting it. The only hopeful possibility is to reduce the dimensions of the coming disaster.

We are being misled by those who say there is a serious food-shortage. This is not true; world food production this decade is the greatest in history. The problem is that there are too many people. The food shortage is simply evidence of the problem. It makes no difference whatever how much food the world produces, if it produces people faster than they can be fed.

Some nations are now on the brink of famine, because their populations have grown beyond the carrying capacity of their lands. Population growth has pushed many of the peoples of Africa, Asia, and Latin America, onto lands which are only marginally suitable for agriculture. No amount of scientific wizardry or improved weather will change this situation.

For a quarter of a century the United States has been generous with its food surpluses, but these have now vanished. This one country has given at least 80 thousand million dollars' worth of food and development aid since World War II. Now what is the result? Today, the developing world is less able to feed itself than it was before the massive U.S. aid programme began. A generation ago, the population of poor countries was increasing by 16 millions a year; now it increases by 67 millions each year and the imbalance grows worse and worse. Furthermore, our past generosity has encouraged a do-nothing policy in the governments of some developing nations. At the 1974 United Nations conferences in Bucharest and Rome, which were concerned with population and food, respectively, spokesmen for these developing nations incredibly asserted that they had no population problem. They defended this with two policy statements that:

1. The hungry nations have the right to produce as many children as they please.

2. Others have the responsibility to feed them.

We believe that these statements are irresponsible and indefensible. Any nation that asserts the right to produce more babies must also assume the responsibility for taking care of them.

Some people speak optimistically of progress within the hungry nations, as evidenced by the modest acceptance of family planning programmes in many countries. 'Family planning will succeed', they tell us. But how is this possible? Family planning advocates, to gain acceptance, insist that parents everywhere may have as many children as they desire. If the number of children wanted had always been two (on the average), we would not now have a population problem. The crisis exists because parents want more than two children. In Moslem countries, for example, the desired number of progeny per couple is 'as many as Allah will send'. This turns out, on the average, to be seven!

The country which has spent the most money on family planning over the longest period of time (India-24 years) has accomplished virtually nothing. Its population in 1951 grew by 3.6 millions. Now it grows by 16.2 millions each year. Mexico adopted family planning only three years ago and the birth-rate there has risen abruptly-according to José Campillo Sainz, Mexican Secretary of Industry and Commerce, in a speech before the U.S.-Mexico Chamber of Commerce, Washington, D.C., 2 December 1974.

Yet many people insist that it is the moral obligation of the United States not only to continue but to increase her aid-totally overlooking the fact that it is impossible, from a practical standpoint. Eighty per cent of the world's grain is not grown in the United States. All that we can sell or give away amounts to only $6 \%$ of the world's production, and less than three years' population increase alone would consume this.

There can be no moral obligation to do the impossible. This does not mean that we advocate 'triage'-the selection of those nations which seem most likely to survive and the concentration of our available food aid on them. Few if any people can really advocate triage. The question would only arise if we should reach the point where the world population outruns food resources. This situation is now being approached, with the world's present stores of grain the lowest since records started to be kept after World War II. If such a situation should actually come about, some people would die-no matter what the disposition of the inadequate food supply might be. In that event, some hard decisions would have to be made.

At some point, people in the United States are going to find that they cannot provide for the world any more than they can police it. In summary, our position is this: The sovereign right of each nation to control its own reproduction creates the reciprocal responsibility to care for its own people. The U.S. can help and will do so, but only to the limits of her available resources.

The belief that the crisis result from a 'shortage' of food leads to disaster. Attempting to deal with this by producing and distributing more food, while doing nothing about population, is incubating disaster. For there are distinct limits to what can be produced on this finite globe. We must not permit our aid to underwrite the failure of some nations to take care of their own situations. If only aiddependent nations could understand that there are limits to North American food resources, there would be hope that they would tackle their population problems in earnest. We owe it to posterity-our own and that of the rest of the world-to promote policies which lead to solutions instead of catastrophe.

Justin Blackwelder, President The Environmental Fund 1302 Eighteenth Street, N.W. Washington D.C. 20036, U.S.A. 